\title{
Impact of Non-Adherence on Renal and Cardiovascular Outcomes in US Veterans
}

\author{
Elvira O. Gosmanova ${ }^{b}$ Miklos Z. Molnar ${ }^{b}$ Ahmed Alrifai $^{\mathrm{b}} \quad$ Jun L. Lu ${ }^{\mathrm{b}}$ Elani Streja ${ }^{a}$ \\ William C. Cushman ${ }^{c, d}$ Kamyar Kalantar-Zadeh ${ }^{a}$ Csaba P. Kovesdy ${ }^{b, e}$ \\ a Division of Nephrology, University of California, Irvine, Calif., ${ }^{b}$ Nephrology Division, Department of Medicine and \\ 'Department of Preventive Medicine, University of Tennessee Health Science Center, ${ }^{d}$ Preventive Medicine and \\ eNephrology Division, Memphis Veterans Affairs Medical Center, Memphis, Tenn., USA
}

\begin{abstract}
Key Words
Non-adherence $\cdot \mathrm{V} 15.81$ code $\cdot$ Chronic kidney disease .

End-stage renal disease $\cdot$ Coronary artery disease $\cdot$ Stroke
\end{abstract}

\begin{abstract}
Background: Adherence is paramount in treating hypertension; however, no gold standard method is available for nonadherence screening, delineating high-risk patients. An International Classification of Diseases 9th Edition non-adherence diagnostic code (V15.81) has been available for decades; but, its utility is poorly studied. We examined the association between the V15.81 code assigned prior to the initiation of anti-hypertensive drugs (AHDs) and renal and cardiovascular outcomes. Methods: This was a historical prospective cohort study involving 312,489 newly treated hypertensive individuals (mean age 53.8 years, $90.9 \%$ males, $20.3 \%$ black, median follow-up 8.0 years). We used crude and Cox models adjusted for baseline socio-demographic characteristics, estimated glomerular filtration rate (eGFR), body mass index, blood pressure, comorbidities, and prospective AHD adherence (measured as proportion of days covered, PDC). $\boldsymbol{R e}$ sults: In the unadjusted analysis, the V15.81 code was associated with higher risks for faster eGFR decline (hazard ratio, HR 1.22, 95\% Cl 1.11-1.33), incident CKD (HR 1.17, 95\% Cl 1.09-1.27), end-stage renal disease (ESRD) (HR 2.53, 95\% Cl 1.72-3.72), incident coronary artery disease (CAD) (HR 1.26, 95\% Cl 1.15-1.38), and stroke (HR 1.55, 95\% Cl 1.38-1.73). In
\end{abstract}

the adjusted model, the V15.81 code remained predictive of increased risk of CKD (HR 1.33, 95\% Cl 1.22-1.45), ESRD (HR $1.81,95 \% \mathrm{Cl} 1.18-2.78)$, incident CAD (HR 1.26, 95\% Cl 1.141.40), and stroke (HR 1.46, 95\% Cl 1.29-1.65). Additional adjustment for PDC did not alter adverse associations between V15.81 code and studied outcomes. Conclusions: Assignment of V15.81 code prior to AHD therapy was associated with higher risks of renal and cardiovascular outcomes in incident hypertensive US veterans. Previous history of non-adherence is a poor prognostic marker in hypertensive individuals; therefore, patients with V15.81 code may require close monitoring. The observational nature of this study limits our ability to make firm recommendations for clinical practice.

(c) 2015 S. Karger AG, Basel

\section{Introduction}

Hypertension (HTN) is the most common chronic medical condition and one of the leading causes of cardiovascular disease and end-stage renal disease (ESRD). Oral anti-hypertensive drugs (AHDs) have unequivocally shown to improve outcomes in hypertensive individuals $[1,2]$. Nevertheless, the rates of BP control remain in need for improvement despite the availability of numerous AHD [3]. It has been increasingly recognized that adherence to AHD is an important mediator of achieving desir-

\section{KARGER 125}

(c) 2015 S. Karger AG, Base

0250-8095/15/0422-0151\$39.50/0

E-Mail karger@karger.com

www.karger.com/ajn
Csaba P. Kovesdy, MD, FASN

Division of Nephrology, Memphis VA Medical Center

1030 Jefferson Ave.

Memphis TN 38104 (USA)

E-Mail ckovesdy@uthsc.edu 
able BP control $[4,5]$. Unfortunately, rates of adherence to AHD remain suboptimal and at least $40 \%$ of patients with HTN are reported to be poor adherers $[6,7]$.

There are several direct and indirect methods for adherence evaluation [8]. A common feature of these methods is that they can be applied after initiation of the AHD therapy. In the mid-1970s, the International Classification of Diseases 9th Edition (ICD-9-CM) introduced a diagnostic code for medical treatment non-adherence -V15.81. We have recently shown that patients who had the V15.81 code established prior to the diagnosis of HTN had subsequently higher all-cause mortality, independent of BP control and adherence to AHD therapy following the diagnosis of HTN [8]. Nonetheless, it is unknown whether the presence of the V15.81 code may also confer heightened risk for renal and cardiovascular outcomes. We investigated the association of the V15.81 code assigned prior to the initiation of AHD with renal and cardiovascular outcomes in a large cohort on incident hypertensive US veterans.

\section{Methods}

\section{Cohort Definition}

The institutional review committees at the Memphis and Long Beach Veterans Affairs Medical Centers approved the study. Data were obtained from the Racial and Cardiovascular Risk Anomalies in the CKD study examining the risk factors of incident CKD in US veterans, which was previously described in detail [9]. Inclusion criteria for the study were (1) patients with diagnosis of incident HTN, (2) baseline estimated glomerular filtration rate (eGFR) $\geq 60 \mathrm{ml} / \mathrm{min} / 1.73 \mathrm{~m}^{2}$ using the Chronic Kidney Disease Epidemiology Collaboration equation, and (3) who initiated one or more major AHD classes ( $\alpha$ - or $\beta$-blockers, calcium channel blockers, thiazide, loop and potassium sparing diuretics, angiotensin converting enzyme inhibitors, and angiotensin receptor blockers) in the outpatient setting after October 1, 2006, preceded by no prescription of any AHDs during October 1, 2004-September 30, 2006, based on information obtained from VA Pharmacy dispensation records [10]. Exclusion criteria were (1) the combined use of all other AHD (peripheral vasodilators, other diuretics, and direct renin inhibitors; $0.26 \%$ ), (2) patients on $\alpha$-blocker monotherapy as we could not ascertain the presence of alternative indications for their use, such as benign prostate hypertrophy $(2.0 \%)$, and (3) patients diagnosed with congestive heart failure (ICD-9CM codes 428.x) or with tachyarrhythmias (ICD-9-CM codes 427.x) (0.4\%). The final cohort comprised 312,489 patients, including 10,401 patients with a V15.81 code assigned prior to the initiation of AHDs and 302,088 patients without a V15.81 code.

Socio-demographic and laboratory characteristics, and comorbid conditions were obtained as previously described [11-18]. Information about age, gender, race, marital status, mean per capita income, and blood pressure (BP) were obtained through the VA Corporate Data Warehouse and from Medicare through the VAMedicare data merge project [14]. Baseline systolic BP (SBP) and diastolic BP (DBP) values were obtained on the date of the first
AHD prescription. Information about comorbidities was collected from the VA Inpatient and Outpatient Medical SAS Datasets using ICD-9-CM diagnostic and procedure codes and Current Procedural Terminology (CPT) codes (online suppl. table 1; for all online suppl. material, see www.karger.com/doi/10.1159/000440685) [13]. Non-adherence was defined as the presence of ICD-9-CM code V15.81 during any inpatient or outpatient encounter preceding the initiation of AHD therapy. In addition, we included selected socioeconomic indicators using 2004 county typology codes (housing stress, low education, low employment and persistent poverty) based on the patients' residential address, obtained from the Area Health Resources Files system issued by the US National Center for Health Workforce Analysis, Bureau of Health Workforce, Health Resources and Services Administration (http://ahrf.hrsa.gov/).

Adherence to AHD was estimated as the percentage of days that a subject had medication available (proportion of days covered, PDC) [8]; this information was collected from medication dispensation records from any VA pharmacy. PDC was calculated as the ratio of the total number of days with medication available on hand and the number of days between the first fill of the medication and the end of the 12-month evaluation period. In patients who were prescribed several AHDs, PDC was calculated as the mean PDC of individual AHDs. Patients were grouped into the following adherence levels: inadequate (PDC $<80 \%)$ and adequate (PDC $\geq 80 \%$ ) [19-21].

\section{Outcomes}

A median follow-up period for the renal and cardiovascular outcomes was 8.0 years. We had three pre-specified renal outcomes: (1) faster rate of eGFR decline, defined by slope of eGFR reduction of more than $5 \mathrm{ml} / \mathrm{min} / 1.73 \mathrm{~m}^{2} /$ year [22], (2) incident $\mathrm{CKD}$, defined as the development of persistent eGFR $<60 \mathrm{ml} /$ $\mathrm{min} / 1.73 \mathrm{~m}^{2}$ ( 2 consecutive measurements separated by $\geq 90$ days), and a $25 \%$ decrease of eGFR from baseline [22], and (3) incident ESRD, defined as the initiation of renal replacement therapy (dialysis or preemptive kidney transplantation). The median (interquartile range) number of serum creatinine measurements used to calculate eGFR slopes was 10 (5-17). Data on ESRD were obtained from the United States Renal Data System (USRDS).

Incident coronary artery disease (CAD) was defined as the composite outcome of a first occurrence of an ICD-9-CM or CPT codes for acute myocardial infarction, coronary artery bypass grafting, or percutaneous angioplasty, and incident stroke were defined as the first occurrence of ICD-9-CM codes for ischemic stroke following October 1, 2006 in patients without such diagnoses prior to this date. Online supplemental tables 2 and 3 list the aforementioned ICD-9-CM and CPT codes for incident CAD and stroke.

\section{Statistical Analysis}

Descriptive analyses were performed and skewed variables were log-transformed. The start of the follow-up period was the date of initial AHD prescription. Patients were followed until the date of last healthcare or administrative visit, or until July 26, 2013.

The association of the V15.81 code with cardiovascular and renal outcomes was assessed using the Kaplan-Meier method and Cox regression models after adjusting for the following confounders: age, gender, race-ethnicity, marital status, mean income level, service-connectedness (a measure indicating whether one or more of a patient's comorbidities were caused by their military service, and resulting in certain privileges such as preferential access to 
Table 1. Baseline characteristics of individuals stratified by ICD-9-CM code for medical treatment non-adherence

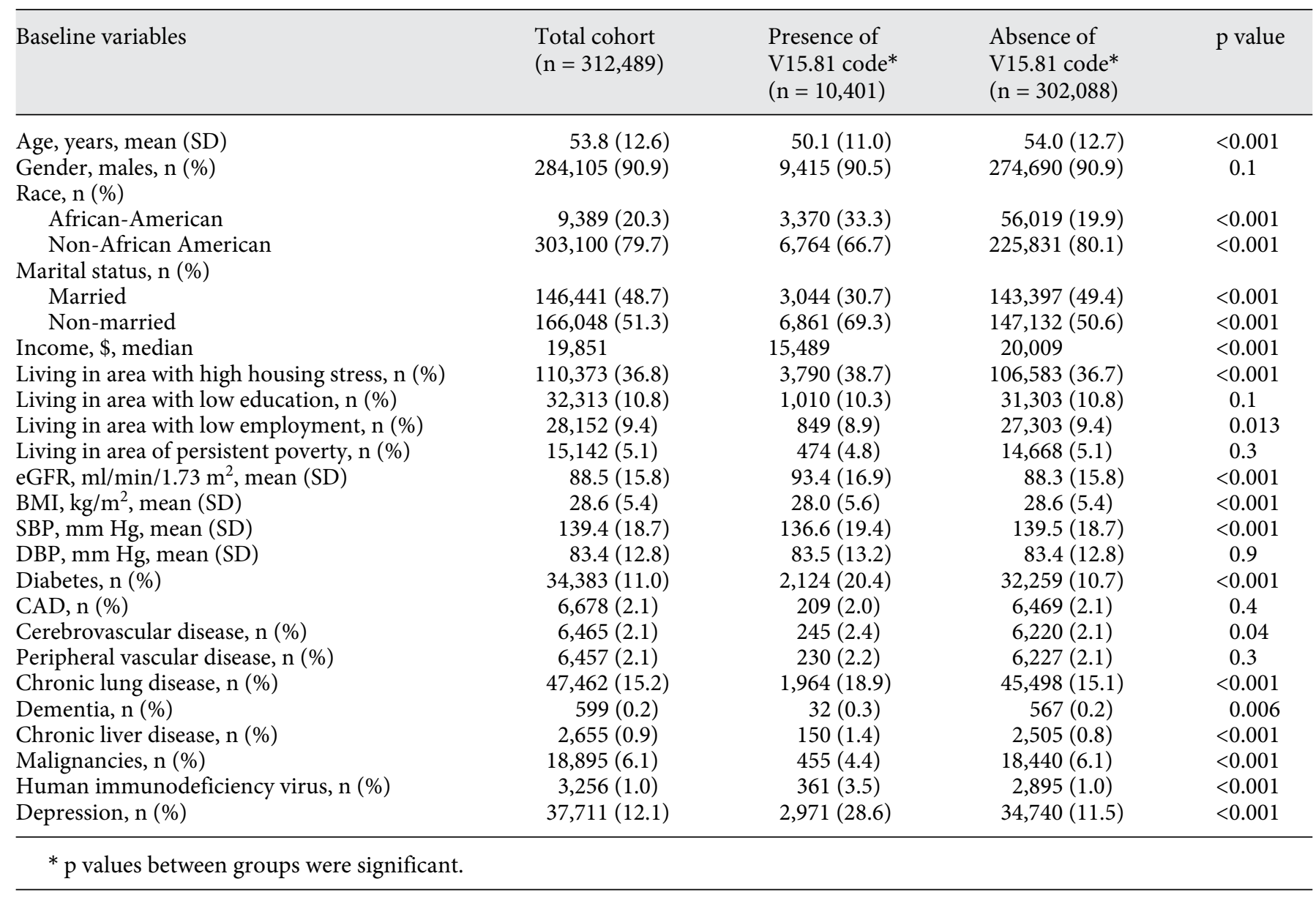

care and lower co-payments), baseline eGFR, body mass index (BMI), SBP and DBP, and comorbid conditions (diabetes, CAD, peripheral artery disease, chronic lung disease, dementia, liver disease, malignancies, HIV/AIDS, and depression). We hypothesized that non-adherence to medication could be in the path of V15.81's effects on all-cause mortality; therefore, we did not include PDC in our main multivariable model, but rather adjusted for this variable in sensitivity analyses.

Analyses were repeated in subgroups of patients categorized by relevant demographic and clinical characteristics.

Statistical analyses were performed using STATA MP version 12 (StataCorp, College Station, Tex., USA).

\section{Results}

\section{Baseline Characteristics}

The mean (SD) age of the total cohort was 53.8 (12.6) years, $90.9 \%$ were males, $20.3 \%$ were black, and $48.7 \%$ were married. Baseline characteristics of the overall cohort and of patients categorized by the presence or ab- sence of V15.81 code are shown in table 1. Patients with V15.81 code were younger, more likely to be black and to be unmarried, and had a lower mean income. Additionally, patients with the V15.81 code had a higher eGFR, a lower BMI and SBP, and a higher prevalence of comorbidities such as diabetes, chronic lung and liver disease, and depression, and a lower prevalence of malignancies.

\section{Renal Outcomes: Faster Slope of eGFR Decline,} Incident CKD, and ESRD

All renal outcomes were significantly higher in incident hypertensive patients with the V15.81 code (table 2). Overall, the faster slope of eGFR decline was seen in 14,974 (4.9\%) patients. Faster eGFR decline was seen in $605(5.9 \%)$ and 14,369 (4.9\%) patients with and without V15.81 code and it corresponded to a $22 \%$ higher risk of faster eGFR decline in the V15.81+ group (unadjusted OR 1.22, 95\% CI 1.12-1.32). Adjustment for baseline demographic characteristics and eGFR did not alter this asso- 
Table 2. HRs of renal outcomes in patients with V15.81 code using unadjusted analysis and various adjusted models

\begin{tabular}{|c|c|c|c|c|c|c|}
\hline \multirow[t]{2}{*}{ Analysis } & \multicolumn{2}{|c|}{ Faster slope of eGFR decline } & \multicolumn{2}{|l|}{ Incident CKD } & \multicolumn{2}{|l|}{ ESRD } \\
\hline & $\mathrm{HR}(95 \% \mathrm{CI})^{*}$ & $\mathrm{p}$ value & $\mathrm{HR}(95 \% \mathrm{CI})^{*}$ & $\mathrm{p}$ value & $\operatorname{HR}(95 \% \mathrm{CI})^{*}$ & $\mathrm{p}$ value \\
\hline Unadjusted analysis & $1.22(1.12-1.32)$ & $<0.001$ & $1.17(1.08-1.27)$ & $<0.001$ & $2.53(1.72-3.72)$ & $<0.001$ \\
\hline Adjusted analysis 1 & $1.20(1.10-1.32)$ & $<0.001$ & $1.50(1.38-1.63)$ & $<0.001$ & $2.19(1.44-3.34)$ & $<0.001$ \\
\hline Adjusted analysis 2 & $1.14(1.04-1.25)$ & 0.006 & $1.53(1.41-1.67)$ & $<0.001$ & $2.22(1.46-3.39)$ & $<0.001$ \\
\hline Adjusted analysis 3 & $1.07(0.98-1.17)$ & 0.1 & $1.33(1.22-1.45)$ & $<0.001$ & $1.81(1.18-2.78)$ & 0.006 \\
\hline Adjusted analysis 4 & $1.07(0.97-1.17)$ & 0.2 & $1.33(1.22-1.45)$ & $<0.001$ & $1.81(1.18-2.78)$ & 0.007 \\
\hline Adjusted analysis 5 & $1.11(0.98-1.26)$ & 0.09 & $1.21(1.08-1.36)$ & 0.002 & $1.91(1.13-3.23)$ & 0.015 \\
\hline
\end{tabular}

*V15.81'-' group served as a reference group for all analyzes. Adjusted analysis $1=$ Adjusted analysis for age, gender, race, mean income, marital status, area-level housing stress, low education, low employment and persistent poverty; adjusted analysis 2 = adjusted analysis 1 plus eGFR; adjusted analysis 3 = adjusted analysis 2 plus baseline comorbidities; adjusted analysis $4=$ adjusted analysis 3 plus baseline systolic and diastolic BP and BMI; adjusted analysis $5=$ adjusted analysis 4 plus adherence to AHDs.

Table 3. HRs of incident CAD and stroke in patients with V15.81 code using unadjusted analysis and various adjusted models

\begin{tabular}{|c|c|c|c|c|}
\hline \multirow[t]{2}{*}{ Analysis } & \multicolumn{2}{|l|}{ Incident CAD } & \multicolumn{2}{|l|}{ Incident stoke } \\
\hline & HR $(95 \% \text { CI })^{*}$ & $\mathrm{p}$ value & $\operatorname{HR}(95 \% \mathrm{CI})^{*}$ & $\mathrm{p}$ value \\
\hline Unadjusted analysis & $1.26(1.15-1.38)$ & $<0.001$ & $1.55(1.38-1.73)$ & $<0.001$ \\
\hline Adjusted analysis 1 & $1.38(1.25-1.52)$ & $<0.001$ & $1.56(1.38-1.76)$ & $<0.001$ \\
\hline Adjusted analysis 2 & $1.38(1.25-1.52)$ & $<0.001$ & $1.54(1.36-1.74)$ & $<0.001$ \\
\hline Adjusted analysis 3 & $1.33(1.20-1.47)$ & $<0.001$ & $1.49(1.32-1.69)$ & $<0.001$ \\
\hline Adjusted analysis 4 & $1.26(1.14-1.40)$ & $<0.001$ & $1.46(1.29-1.65)$ & $<0.001$ \\
\hline Adjusted analysis 5 & $1.35(1.17-1.57)$ & $<0.001$ & $1.55(1.30-1.85)$ & $<0.001$ \\
\hline
\end{tabular}

*V15.81'-' group served as a reference group for all analyzes. Adjusted analysis $1=$ Adjusted analysis for age, gender, race, mean income, marital status, area-level housing stress, low education, low employment and persistent poverty; adjusted analysis 2 = adjusted analysis 1 plus eGFR; adjusted analysis $3=$ adjusted analysis 2 plus baseline comorbidities; adjusted analysis $4=$ adjusted analysis 3 plus baseline systolic and diastolic BP and BMI; adjusted analysis $5=$ adjusted analysis 4 plus adherence to AHDs.

ciation; however, addition to the adjusted model of baseline BP, BMI, and comorbidities lead to the attenuation of increased risk of faster eGFR decline in the V15.81' +' cohort (adjusted hazard ratio, HR 1.07, 95\% CI 0.98-1.17).

Incident CKD developed in 16,359 (5.2\%) patients (event rate 7.1 (7.0-7.2)/1,000 patient-years). Incident CKD occurred in $634(6.1 \%$, event rate $8.1(7.5-8.8) / 1,000$ patient-years, and $15,725(5.2 \%$, event rate $7.0(6.9-$ $7.1) / 1,000$ patient-years) patients with and without the V15.81 code, respectively. The presence of the V15.81 code was associated with a $17 \%$ higher risk of incidence CKD in unadjusted analysis (unadjusted HR 1.17, 95\% CI $1.08-1.27$ ), and a $33 \%$ higher risk in fully adjusted analysis (adjusted HR 1.33, 95\% CI 1.22-1.45).

The development of ESRD was an infrequent event and occurred in $390(0.12 \%)$ patients in the total cohort (event rate $0.15(0.13-0.16) / 1,000$ patient-years). Nevertheless, patients with the V15.81 code were 2.5 times more likely to develop ESRD as compared to patients without the V15.81 code: event rate $0.35(0.24-0.50) / 1,000$ patientyears and $0.14(0.13-0.16) / 1,000$ patient-years in the V15.81'+' and V15.81'-' groups, respectively (unadjusted HR 2.53, 95\% CI 1.72-3.72, p < 0.001). Adjustments for confounders only marginally diminished the increased risk of ESRD in patients with the V15.81 code (table 2).

The risks of incident CKD and ESRD were increased in patients with the V15.81 code and higher baseline eGFR (online suppl. fig. 1).

\section{Incident CAD and Incident Stroke}

Similarly to renal outcomes, incident CAD and stroke were adversely associated with the presence V15.81 code in newly treated hypertensive individuals (table 3 ). A total of 10,749 patients $(3.5 \%$, event rate $4.6(4.5-4.7) / 1,000$ 
patient-years) developed incident CAD. There were 457 incident CAD events in the group with the V15.81 (4.4\%, event rate 5.7 (5.2-6.3)/1,000 patient-years) and 10,292 incident CAD events in the group without V15.81 (3.4\%, event rate 4.5 (4.4-4.6)/1,000 patient-years). The presence of V15.81 was associated with $26 \%$ higher risk of incident CAD (HR 1.26, 95\% CI 1.15-1.38, p < 0.001) in unadjusted analysis. Incident stroke occurred in $6,111 \mathrm{pa}-$ tients $(2.0 \%$, event rate $2.6(2.5-2.7) / 1,000$ patient-years). The event rates of incident stroke were $4.0(3.6-4.5) / 1,000$ patient-years (3.1\%) and 2.5 (2.4-2.6)/1,000 patient-years $(2.0 \%)$ in patients with and without the V15.81 code, respectively. In unadjusted analysis, patientsin the V15.81'+' group had 55\% higher risk of incident stroke (unadjusted HR $1.55,95 \%$ CI 1.38-1.74, $\mathrm{p}<0.001$ ), as compared with the V15.81'-' group. The higher risks of incident CAD and stroke remained unchanged in patients with the V15.81 code after adjustment for confounders (table 3 ).

The presence of the V15.81 code was associated with increased risk for CAD and stroke in the majority of studied subgroups (online suppl. fig. 2).

\section{Effect of Follow-Up Adherence to AHD on the}

Association between the V15.81 Code and CV and

\section{Renal Outcomes}

The mean (SD) adherence to AHD as defined by PDC was $83.3 \%(17.5 \%)$ in the whole cohort. Adequate adherence (PDC $\geq 80 \%$ ) was present in 63.2 and $61.2 \%$ of patients with and without the V15.81 code. The inclusion of PDC into Cox model did not alter the original associations between the V15.81 code and renal and cardiovascular outcomes (tables 2, 3).

\section{Discussion}

We examined the effects of the ICD-9-CM code for medical treatment non-adherence (V15.81) that was assigned prior to the initiation of AHD therapy on renal and cardiovascular outcomes in a large cohort of US veterans with newly treated HTN. Patients with past history of nonadherence had a higher likelihood of incident CKD and ESRD, and a marginally faster decline of eGFR over time, as well as an increased risk of incident CAD and stroke.

The V15.81 code was introduced into ICD-9-CM in the mid-1970s $[8,23]$. Its original definition included 'personal history presenting hazard to health and noncompliance with medical treatment' and the V15.81 code was intended to describe diverse behaviors influencing treatment outcomes (e.g. non-adherent medication-tak-

V15.81 and Renal and Cardiovascular Outcomes ing behavior, non-adherence with diet, appointments, unwillingness to stop hazardous health habits, and noncompliance with preventive measures). Therefore, the V15.81 code cannot delineate the non-adherent behavioral component that leads to the assignment of this diagnosis. The International Classification of Diseases 10th Revision acknowledged the complex nature of nonadherence and incorporated 8 non-adherence codes (Z91.11-Z91.19), including diagnoses such as voluntary and involuntary non-adherence with medications, diet, dialysis, and other (unspecified) non-adherence. Hopefully, the future use of International Classification of Diseases 10th Revision non-adherence-related codes may allow better understanding of the effects the various aspects of adherence may have on health outcomes.

It is unlikely, that patients themselves would report medical diagnosis of non-adherence in the same way that they would report a history of a disease such as diabetes. However, once recorded in the electronic medical record, a previous history is generally easily accessible. Therefore, the presence of the V15.81 code in a patient initiating AHD can allow providers to identify high-risk patients for a wide variety of adverse outcomes and alert for a need of closer attention to these individuals. Patients with the V15.81 code assigned prior to the initiation of AHD were not at higher risk for subsequent inadequate adherence to AHD. Nevertheless, the V15.81 code conferred increased risk of adverse renal and cardiovascular outcomes after the adjustment to AHD adherence. Similarly, we recently reported that newly treated hypertensive individuals with the V15.81 code had augmented all-cause mortality independent from follow-up levels of BP or adherence to AHD [9]. The V15.81 code was present prior to the initiation of AHD therapy; hence, its assignment might have been induced by behavioral patterns that are independent from subsequent adherence to AHD effects. This further underscores the complex nature of adherence and emphasizes that its assessment and any interventions need to have a broad scope and focus on patient behaviors beyond medication adherence. This study reinforces the usefulness of routine addition of the medical non-adherence code to patients' histories where inadequate adherence is suspected.

To our knowledge, no previous studies have so far evaluated the predictive utility of non-adherence diagnostic code on cardiovascular and renal outcomes. However, non-adherence, established via analysis of pharmacy databases - a widely used method for the evaluation of outcomes related to medication-taking behavior in HTN - was previously linked to adverse cardiovascular and renal outcomes $[4,21]$. Good adherence was linked 
to a $22 \%$ reduction in rates of cerebrovascular disease during a median of 3.3 years of follow-up in a cohort of 83,267 hypertensive individuals (relative risk, RR 0.78, 95\% CI 0.70-0.87) [24]; while, poor adherence with AHD was associated with a $15 \%$ higher risk of acute myocardial infarction (RR 1.15, 95\% CI 1.00-1.33) and a $28 \%$ increase in risk of stroke (RR 1.28, 95\% CI 1.15-1.45) among 77,193 newly treated hypertensive patients during 4 years of follow-up [25]. Similarly, 2- and 10-year strokerelated mortality was 3.8- and 3.0-fold higher (OR 3.8, 95\% CI 2.85-5.10 and OR 3.01, 95\% CI 2.27-3.83, respectively) in incident AHD users with adherence to AHD of $<80 \%$ [26]. A single study examining the association between the adherence to AHD assessed via pharmacy database and incidence of ESRD found a 33\% higher risk of ESRD in patients with compliance of $<80 \%$, as compared with $\geq 80 \%$ during a median of 5.1 years of follow-up [21]. The findings of the present study complement findings by Roy et al. [21] demonstrating an elevated risk of incident CKD and ESRD in the presence of non-adherence in newly treated hypertensive veterans. Pharmacy databases allow the assessment of only the medication-taking aspect of adherence. In contrast, the V15.81 code could be a more global descriptor of non-adherent behavior, and the use of a diagnostic non-adherence code requires only a review of previous medical history.

\section{Strength and Limitations}

This is the first study to investigate the association between the ICD-9 code for medical treatment non-adherence (V15.81) and renal and cardiovascular outcomes in newly treated hypertensive patients. This study has several limitations. Although we reported an association between the V15.81 code and renal and cardiovascular outcomes, no causal conclusions could be made. Additionally, given the complex nature of non-adherence and the lack of information about the reasons behind the assignment of V15.81 code, we cannot conclude as to which aspect of non-adherence was responsible for the adverse association between the V15.81 code and health-related outcome. We did not evaluate the follow-up level of BP as possible mediators of worse cardiovascular and kidney outcomes. Nonetheless, we have recently shown that the presence of the V15.81 code before the initiation of AHD was associated with $38 \%$ higher risk of all-cause mortality in incident hypertensive individuals, and follow-up BP levels did not explain the differences in mortality in patients with the V15.81 code [9]. Not all variables influencing cardiovascular and renal outcomes such as smoking and alcohol use were assessed because this information could not be ascertained from our database. The assignment of the V15.81 code is not standardized; however, the overall use of V15.81 code among providers between different geographic regions was not clinically different and varied between 3 and $11.3 \%$ (median $6.3 \%$, interquartile range $5.8-7.7 \%$ ). We did not collect information about albuminuria and, therefore, could not assess the development of earlier stages of CKD. The information about incident ESRD events was obtained from the USRDS; however, a potential survival bias was reported with this database because patients who die soon after initiating dialysis might not be enrolled into the USRDS [27]. Nevertheless, this study strengthens the importance of using medical coding of non-adherence in routine clinical practice and is based on data from a large cohort representative of veterans from the entire geographic United States.

\section{Conclusions}

The V15.81 diagnostic code for medical treatment non-adherence from ICD-9-CM assigned prior to AHD therapy was independently associated with increased risk of renal outcomes such as the development of incident CKD and ESRD, as well the higher risk of cardiovascular disease as defined by incident CAD and stroke in a large cohort of 312,489 incident hypertensive individuals. Non-adherence assessed via a medical diagnostic coding can be a useful 'marker' of increased cardiovascular and renal risks among newly treated hypertensive individuals.

\section{Acknowledgments}

The authors thank Praveen K. Potukuchi for the graphical support during preparation of supplemental figures.

\section{Disclosure Statement}

C.P.K. and K.K.-Z. are employees of the Department of Veterans Affairs. Opinions expressed in this paper are those of the authors' and do not necessarily represent the opinion of the Department of Veterans Affairs. The results of this paper have not been published previously in whole or part.

\section{Funding Source}

This study was supported by grant R01DK096920 to C.P.K. and K.K.-Z. and is the result of work supported with resources and the use of facilities at the Memphis VA Medical Center and the 
Long Beach VA Medical Center. Support for VA/CMS data is provided by the Department of Veterans Affairs, Veterans Health Administration, Office of Research and Development, Health Services Research and Development, VA Information Resource Center (Project Numbers SDR 02-237 and 98-004).

\section{Conflict of Interest}

There are no relevant conflicts to disclose.

\section{References}

1 James PA, Oparil S, Carter BL, Cushman WC, Dennison-Himmelfarb C, Handler J, Lackland DT, LeFevre ML, MacKenzie TD, Ogedegbe O, Smith SC Jr, Svetkey LP, Taler SJ, Townsend RR, Wright JT Jr, Narva AS, Ortiz E: 2014 evidence-based guideline for the management of high blood pressure in adults: report from the panel members appointed to the eighth joint national committee (JNC 8). JAMA 2014;311:507-520.

-2 Staessen JA, Gasowski J, Wang JG, Thijs L, Den Hond E, Boissel JP, Coope J, Ekbom T, Gueyffier F, Liu L, Kerlikowske K, Pocock S, Fagard RH: Risks of untreated and treated isolated systolic hypertension in the elderly: meta-analysis of outcome trials. Lancet 2000; 355:865-872.

-3 Go AS, Mozaffarian D, Roger VL, Benjamin EJ, Berry JD, Blaha MJ, Dai S, Ford ES, Fox CS, Franco S, Fullerton HJ, Gillespie C, Hailpern SM, Heit JA, Howard VJ, Huffman MD, Judd SE, Kissela BM, Kittner SJ, Lackland DT, Lichtman JH, Lisabeth LD, Mackey RH, Magid DJ, Marcus GM, Marelli A, Matchar DB, McGuire DK, Mohler ER 3rd, Moy CS, Mussolino ME, Neumar RW, Nichol G, Pandey DK, Paynter NP, Reeves MJ, Sorlie PD, Stein J, Towfighi A, Turan TN, Virani SS, Wong ND, Woo D, Turner MB; American Heart Association Statistics Committee and Stroke Statistics Subcommittee: Heart disease and stroke statistics - 2014 update: a report from the American heart association. Circulation 2014;129:e28-e292.

4 Ho PM, Bryson CL, Rumsfeld JS: Medication adherence: its importance in cardiovascular outcomes. Circulation 2009;119:3028-3035.

5 Adherence to Long Term Therapies: Evidence for Action. Geneva, World Health Organization, 2003. http://wwwwhoint/chp/ knowledge/publications/adherence_introductionpdf (accessed on November 20, 2014).

-6 Fitz-Simon N, Bennett K, Feely J: A review of studies of adherence with antihypertensive drugs using prescription databases. Ther Clin Risk Manag 2005;1:93-106.

7 Mazzaglia G, Mantovani LG, Sturkenboom MC, Filippi A, Trifirò G, Cricelli C, Brignoli O, Caputi AP: Patterns of persistence with antihypertensive medications in newly diagnosed hypertensive patients in Italy: a retro- spective cohort study in primary care. J Hypertens 2005;23:2093-2100.

8 Gosmanova EO, Kovesdy CP: Adherence to antihypertensive medications: is prescribing the right pill enough? Nephrol Dial Transplant 2014;pii:gfu330.

-9 Gosmanova EO, Lu JL, Streja E, Cushman WC, Kalantar-Zadeh K, Kovesdy CP: Association of medical treatment nonadherence with all-cause mortality in newly treated hypertensive us veterans. Hypertension 2014; 64:951-957.

10 US Department of Veterans Affairs VIRCVVRUGVPPD, ed 2. Hines, VIReC, 2008.

11 Kovesdy CP, Lott EH, Lu JL, Malakauskas SM, Ma JZ, Molnar MZ, Kalantar-Zadeh K: Hyponatremia, hypernatremia, and mortality in patients with chronic kidney disease with and without congestive heart failure. Circulation 2012;125:677-684.

12 Kovesdy CP, Lott EH, Lu JL, Malakauskas SM, Ma JZ, Molnar MZ, Kalantar-Zadeh K: Outcomes associated with microalbuminuria: effect modification by chronic kidney disease. J Am Coll Cardiol 2013;61:1626-1633.

13 VIReC Research User Guide: VHA Medical SAS Inpatient Datasets FY 2006-2007. Hines IUSDoVAVIRC, 2007.

14 VIReC: US Department of Veterans Affairs VA Information Resource Center Data Quality Update: Race. Hines IUSDoVA, 2009.

15 Kovesdy CP, Bleyer AJ, Molnar MZ, Ma JZ, Sim JJ, Cushman WC, Quarles LD, KalantarZadeh K: Blood pressure and mortality in U.S. Veterans with chronic kidney disease: a cohort study. Ann Intern Med 2013;159:233242.

16 Kovesdy CP, Lu JL, Molnar MZ, Ma JZ, Canada RB, Streja E, Kalantar-Zadeh K, Bleyer AJ: Observational modeling of strict vs conventional blood pressure control in patients with chronic kidney disease. JAMA Intern Med 2014;174:1442-1449.

17 Lu JL, Kalantar-Zadeh K, Ma JZ, Quarles LD, Kovesdy CP: Association of body mass index with outcomes in patients with CKD. J Am Soc Nephrol 2014;25:2088-2096.

18 Molnar MZ, Kalantar-Zadeh K, Lott EH, Lu JL, Malakauskas SM, Ma JZ, Quarles DL,
Kovesdy CP: Angiotensin-converting enzyme inhibitor, angiotensin receptor blocker use, and mortality in patients with chronic kidney disease. J Am Coll Cardiol 2014;63:650-658.

19 Chowdhury R, Khan H, Heydon E, Shroufi A, Fahimi S, Moore C, Stricker B, Mendis S, Hofman A, Mant J, Franco OH: Adherence to cardiovascular therapy: a meta-analysis of prevalence and clinical consequences. Eur Heart J 2013;34:2940-2948.

20 Degli Esposti L, Saragoni S, Benemei S, Batacchi P, Geppetti P, Di Bari M, Marchionni N, Sturani A, Buda S, Degli Esposti E: Adherence to antihypertensive medications and health outcomes among newly treated hypertensive patients. Clinicoecon Outcomes Res 2011;3: 47-54.

21 Roy L, White-Guay B, Dorais M, Dragomir A, Lessard M, Perreault S: Adherence to antihypertensive agents improves risk reduction of end-stage renal disease. Kidney Int 2013;84: 570-577.

22 KDIGO: KDIGO 2012 clinical practice guideline for the evaluation and management of chronic kidney disease. Kidney Int Suppl 2013;3:1-150.

23 Marcum ZA, Sevick MA, Handler SM: Medication nonadherence: a diagnosable and treatable medical condition. JAMA 2013;309: 2105-2106.

24 Kettani FZ, Dragomir A, Côté R, Roy L, Bérard A, Blais L, Lalonde L, Moreau P, Perreault $S$ : Impact of a better adherence to antihypertensive agents on cerebrovascular disease for primary prevention. Stroke 2009;40:213-220.

25 Breekveldt-Postma NS, Penning-van Beest FJ, Siiskonen SJ, Falvey H, Vincze G, Klungel $\mathrm{OH}$, Herings RM: The effect of discontinuation of antihypertensives on the risk of acute myocardial infarction and stroke. Curr Med Res Opin 2008;24:121-127.

26 Herttua K, Tabák AG, Martikainen P, Vahtera J, Kivimäki M: Adherence to antihypertensive therapy prior to the first presentation of stroke in hypertensive adults: populationbased study. Eur Heart J 2013;34:2933-2939.

27 Foley RN, Collins AJ: The USRDS: what you need to know about what it can and can't tell us about ESRD. Clin J Am Soc Nephrol 2013; 8:845-851. 